Case Report

\title{
Deep Venous Reflux Associated with a Dilated Popliteal Fossa Vein Reversed with Endovenous Laser Ablation and Sclerotherapy
}

\author{
Daniel P. Link, Jennifer Feneis, and John Carson \\ Department of Vascular Surgery, University of California Davis School of Medicine, 4860 Y Street, STE 3400, \\ Sacramento, CA 95817, USA \\ Correspondence should be addressed to Daniel P. Link; daniel.link@ucdmc.ucdavis.edu
}

Received 30 July 2013; Accepted 4 September 2013

Academic Editors: R. Dammers, E. Z. Kapsalaki, and D. Tsetis

Copyright (C) 2013 Daniel P. Link et al. This is an open access article distributed under the Creative Commons Attribution License, which permits unrestricted use, distribution, and reproduction in any medium, provided the original work is properly cited.

Objective. To report an incidence of reflux in the deep venous system reversed by ablation of a popliteal fossa vein (PFV). Method. A 40-year-old man with pain and swelling in the medial upper calf was found to have an incompetent PFV. Results. Reflux in the femoral and popliteal veins was reversed utilizing endovenous laser ablation and foam sclerotherapy, documented on Duplex studies before and after the intervention. There was also resolution of symptoms. Conclusion. A PFV can be associated with deep venous reflux. Correction of this reflux with ablation of the PFV suggests that his type of reflux is secondary to volume effects of the incompetent popliteal vein.

\section{Introduction}

The popliteal fossa vein (PFV) has been described as a tributary of the popliteal vein found in the popliteal fossa, which is anatomically distinct from the great and small saphenous veins $[1,2]$. Classified as a perforating vein at the precongress meeting of the Fourteenth World Congress of the International Union of Phlebology (IUP) in 2001, PFV perforates the muscular fascia to connect superficial veins with deep veins, namely, the popliteal vein [1-3]. The prevalence of reflux in a PFV has varied between $8 \%$ in patients with nonsaphenous venous reflux [1] and $1 \%$ in patients with primary varicose veins [4]. This case presents a patient with a dilated PFV, with associated symptomatic venous insufficiency and deep venous reflux, reversed with endovenous laser ablation (EVLT) and sclerotherapy.

\section{Case Information}

A 40-year-old man presented to the Vascular Center Clinic with symptomatic chronic venous insufficiency (CVI). The patient began experiencing cramping and swelling in his right leg seven years prior, with worsening symptoms over the past two years. Upon initial physical exam, the patient was noted to have 1+ edema, hyperpigmentation in the "gaiter zone" distribution, and varicosities on the posterior and medial aspect of the right knee (C4a) [5] (VCSS: skin pigmentation 2 , inflammation 1 , induration 2 , active ulceration 0 , and compression 3) [6, 7], as shown in Figure 1 [5]. After 14 weeks of compression therapy with thigh-high compression hose, the patient returned to clinic with no significant change in symptoms. Physical exam at the time of the followup revealed a mild increase in the venous stasis pigmentation of the right gaiter zone, with no associated edema or ulceration. Venous color duplex ultrasonography of the right lower extremity at this visit revealed reflux in the common femoral, femoral and popliteal veins. The degree of reflux increased dramatically to the popliteal vein, Figures 3(a) and 3(b). The reflux in the popliteal vein and femoral vein was greater than $5 \mathrm{sec}$ standing with augmentation. The velocities were higher in the popliteal vein. Our laboratory considers reflux greater than 5 seconds significant under these conditions. A large perforating vein from the popliteal fossa, demonstrated in Figure 2, connected the dilated subdermal veins in the medial calf to the popliteal vein approximately $40 \mathrm{~cm}$ superior to the medial malleolus (6.4 $\mathrm{mm}$ at the fascial plane). EVLT of 


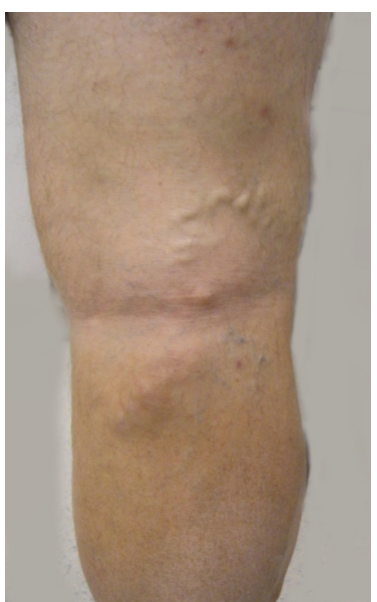

FIgure 1: Photograph of leg demonstrating posterior popliteal varicosities and venous stasis pigmentation.

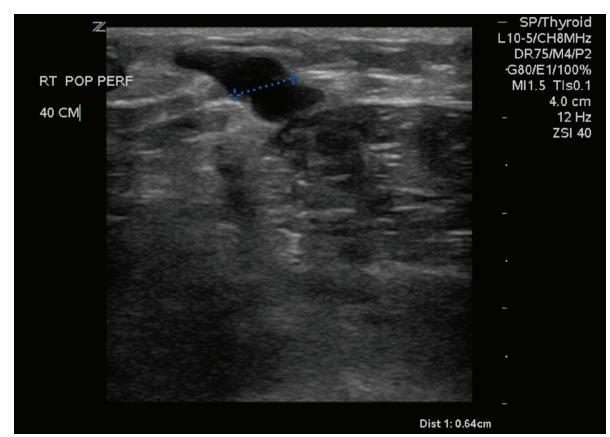

Figure 2: Popliteal fossa vein entering the deep fascia $40 \mathrm{~cm}$ from the medial malleolus, $6.4 \mathrm{~mm}$ at the fascial plane.

the large popliteal fossa vein was performed; 432 joules at 14 watts were applied over a $3 \mathrm{~cm}$ section of vein using an EVLT Perforator Vein Ablation Kit (Diomed Inc., Andover, MA, USA). Foam sclerotherapy with $2 \mathrm{ml}$ of $0.5 \%$ sodium tetradecyl sulfate (AngioDynamics, NY, USA) of the large mid-calf varicosities immediately followed the EVLT. The treatment resulted in resolution of the patient's right leg pain and reflux in the common femoral vein. Two month followup demonstrated near complete resolution of the reflux in the femoral and popliteal veins on repeat Duplex scan, as demonstrated in Figure 3. All terminology this report conforms with standards based on Caggiati et al. $[3,8]$.

\section{Discussion}

PFV reflux has been previously demonstrated to be associated with higher rates of proximal, distal, superficial, perforator, and complex pattern reflux as compared to limbs without PFV; however, the prevalence of deep reflux was not statistically different between the two groups [2]. Treatment of incompetent perforating veins has previously focused on using subfascial endoscopic perforating vein surgery (SEPS) and sclerotherapy [9-11].

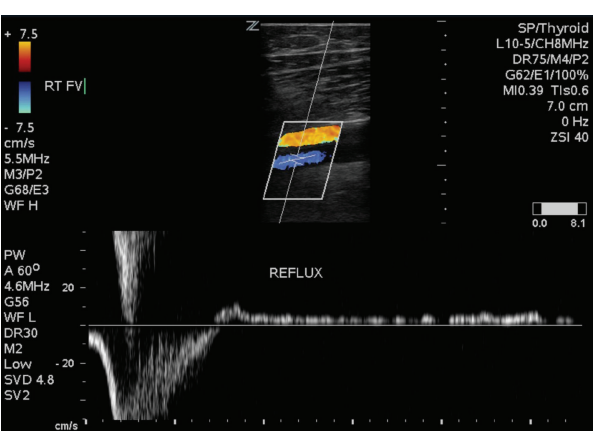

(a)

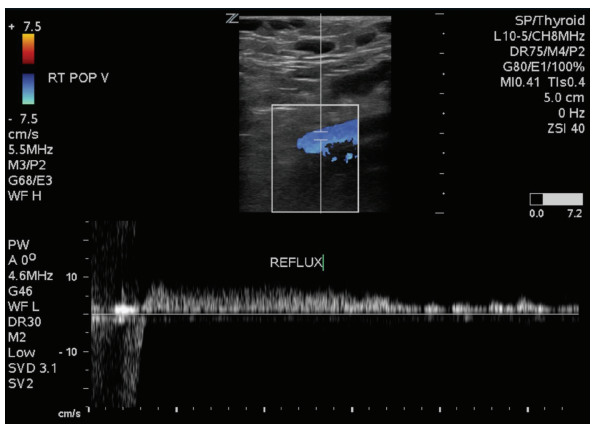

(b)

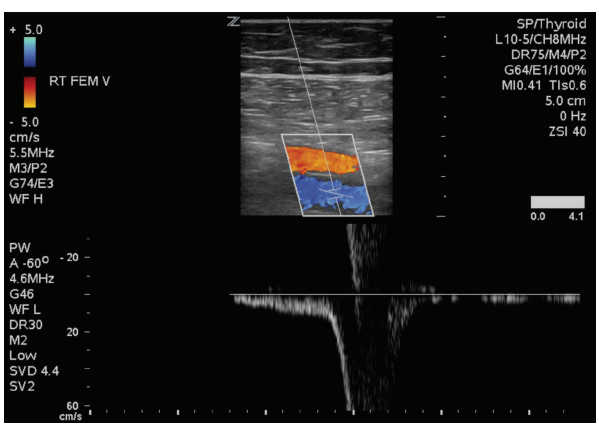

(c)

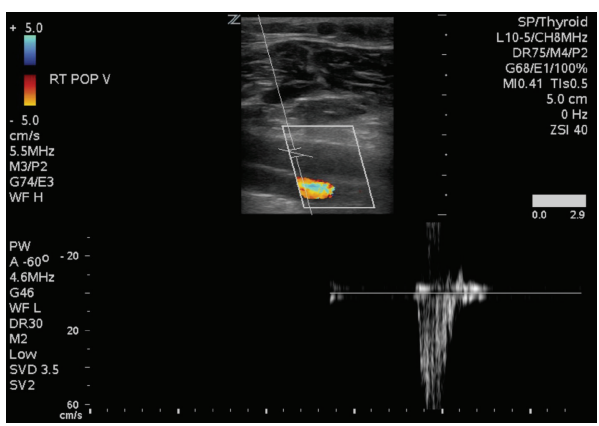

(d)

Figure 3: Pre procedure Duplex of the right femoral v. (a) and right popliteal v. (b); Post procedure Duplex of the right femoral v. (c) and right popliteal v. (d).

In this case, an incompetent popliteal fossa vein led to a large complex of pressurized subdermal veins as well as reflux in the femoral and popliteal veins. It is likely that a proximal calf perforating vein such as a popliteal fossa vein would produce more pressure in the subdermal calf veins than similar sized more distal veins [12]. It is unclear if 
either EVLT or sclerotherapy alone could have resulted in the identical ideal outcome at 1 year after procedure. The addition of the sclerotherapy seemed appropriate to reduce the rate of recurrent symptoms [13]. Reflux in the deep veins was reversed with EVLT of the PFV, which implies that the valve leaflets of the deep veins were not permanently damaged. It is likely that the incompetent PFV first created the subdermal varicosities, and as the venous hypertension continued, the deep veins became engorged as well. This venous volume overload leads to dilatation of the deep veins, rendering their valves incapable of stopping the backflow of blood in the relaxed state. When EVLT successfully obliterated the incompetent PFV, it reduced the overflow into the deep venous system, decreasing the diameter of the deep veins and allowing their valves to return to a functional state. The valve leaflets must have been still intact, or the reflux would not have been able to be reversed. This condition, occurring with an incompetent PFV, may be more prevalent than previously reported. Once identified, it may be effectively treated with minimally invasive techniques.

\section{References}

[1] N. Labropoulos, J. Tiongson, L. Pryor et al., "Nonsaphenous superficial vein reflux," Journal of Vascular Surgery, vol. 34, no. 5, pp. 872-877, 2001.

[2] K. T. Delis, A. L. Knaggs, J. T. Hobbs, and M. A. Vandendriessche, "The nonsaphenous vein of the popliteal fossa: prevalence, patterns of reflux, hemodynamic quantification, and clinical significance," Journal of Vascular Surgery, vol. 44, no. 3, pp. 611619, 2006.

[3] A. Caggiati, J. J. Bergan, P. Gloviczki, G. Jantet, C. P. WendellSmith, and H. Partsch, "Nomenclature of the veins of the lower limbs: an international interdisciplinary consensus statement," Journal of Vascular Surgery, vol. 36, no. 2, pp. 416-422, 2002.

[4] M. Garcia-Gimeno, S. Rodríguez-Camarero, S. Tagarro-Villalba et al., "Duplex mapping of 2036 primary varicose veins," Journal of Vascular Surgery, vol. 49, no. 3, pp. 681-689, 2009.

[5] B. Eklof, R. B. Rutherford, J. J. Bergan et al., "Revision of the CEAP classification for chronic venous disorders: consensus statement," Journal of Vascular Surgery, vol. 40, no. 6, pp. 12481252, 2004.

[6] M. A. Vasquez, E. Rabe, R. B. McLafferty et al., "Revision of the venous clinical severity score: venous outcomes consensus statement: special communication of the American Venous Forum Ad Hoc Outcomes Working Group," Journal of Vascular Surgery, vol. 52, no. 5, pp. 1387-1396, 2010.

[7] R. B. Rutherford, F. T. Padberg Jr., A. J. Comerota, R. L. Kistner, M. H. Meissner, and G. L. Moneta, "Venous severity scoring: an adjunct to venous outcome assessment," Journal of Vascular Surgery, vol. 31, no. 6, pp. 1307-1312, 2000.

[8] A. Caggiati, J. J. Bergan, P. Gloviczki, B. Eklof, C. Allegra, and H. Partsch, "Nomenclature of the veins of the lower limb: extensions, refinements, and clinical application," Journal of Vascular Surgery, vol. 41, no. 4, pp. 719-724, 2005.

[9] A. C. W. Ting, S. W. K. Cheng, P. Ho, J. T. C. Poon, L. L. H. $\mathrm{Wu}$, and G. C. Y. Cheung, "Reduction in deep vein reflux after concomitant subfascial endoscopic perforating vein surgery and superficial vein ablation in advanced primary chronic venous insufficiency," Journal of Vascular Surgery, vol. 43, no. 3, pp. 546-550, 2006.
[10] P. A. F. A. van Neer, J. C. J. M. Veraart, and H. A. M. Neumann, "Venae perforantes: a clinical review," Dermatologic Surgery, vol. 29, no. 9, pp. 931-942, 2003.

[11] L. Blomgren, G. Johansson, A. Dahlberg-Åkerman, P. Thermaenius, and D. Bergqvist, "Changes in superficial and perforating vein reflux after varicose vein surgery," Journal of Vascular Surgery, vol. 42, no. 2, pp. 315-320, 2005.

[12] C. Recek, "Venous pressure gradients in the lower extremity and the hemodynamic consequences," Journal of Vascular Diseases, vol. 39, no. 4, pp. 292-297, 2010.

[13] P. Pittaluga, S. Chastanet, T. Locret, and O. Rousset, "Retrospective evaluation of the need of a redo surgery at the groin for the surgical treatment of varicose vein," Journal of Vascular Surgery, vol. 51, no. 6, pp. 1442-1450, 2010. 


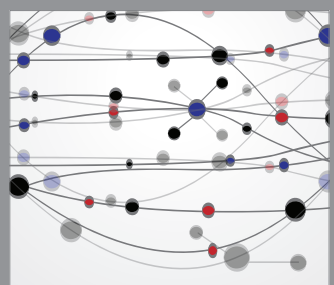

The Scientific World Journal
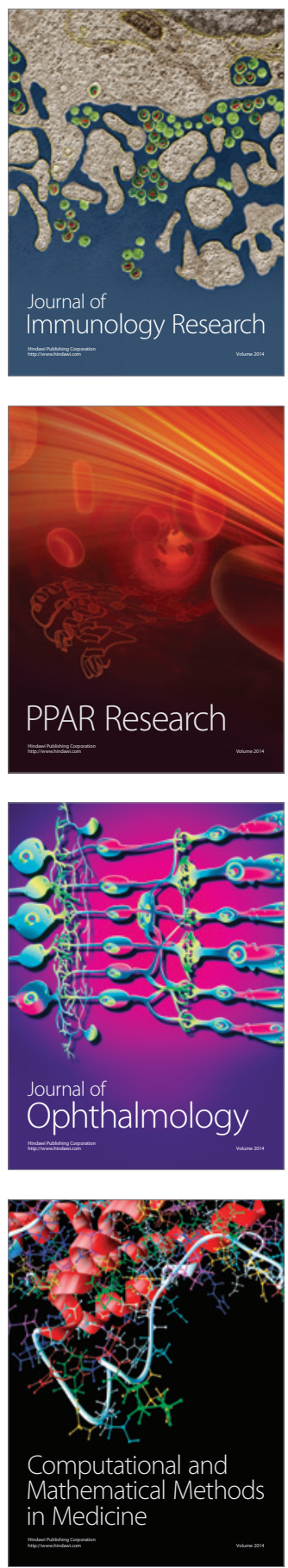

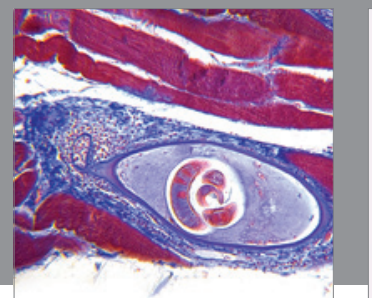

Gastroenterology

Research and Practice
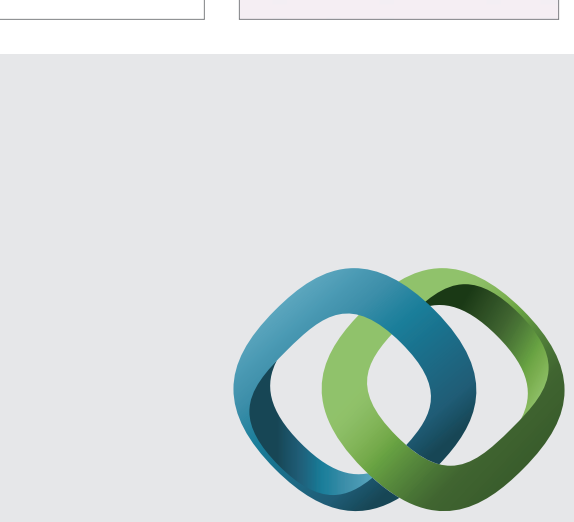

\section{Hindawi}

Submit your manuscripts at

http://www.hindawi.com
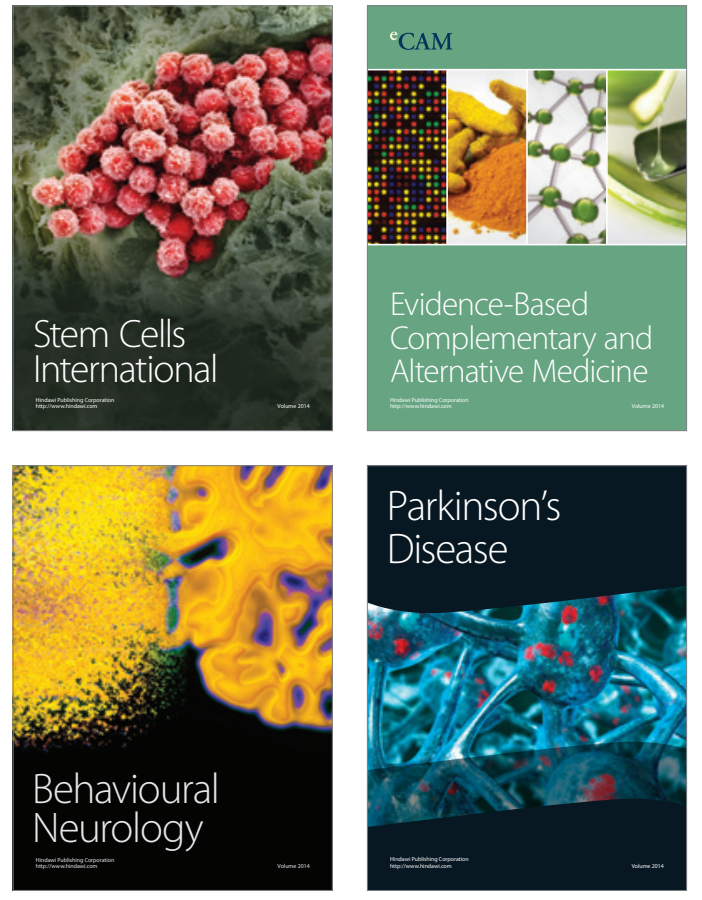
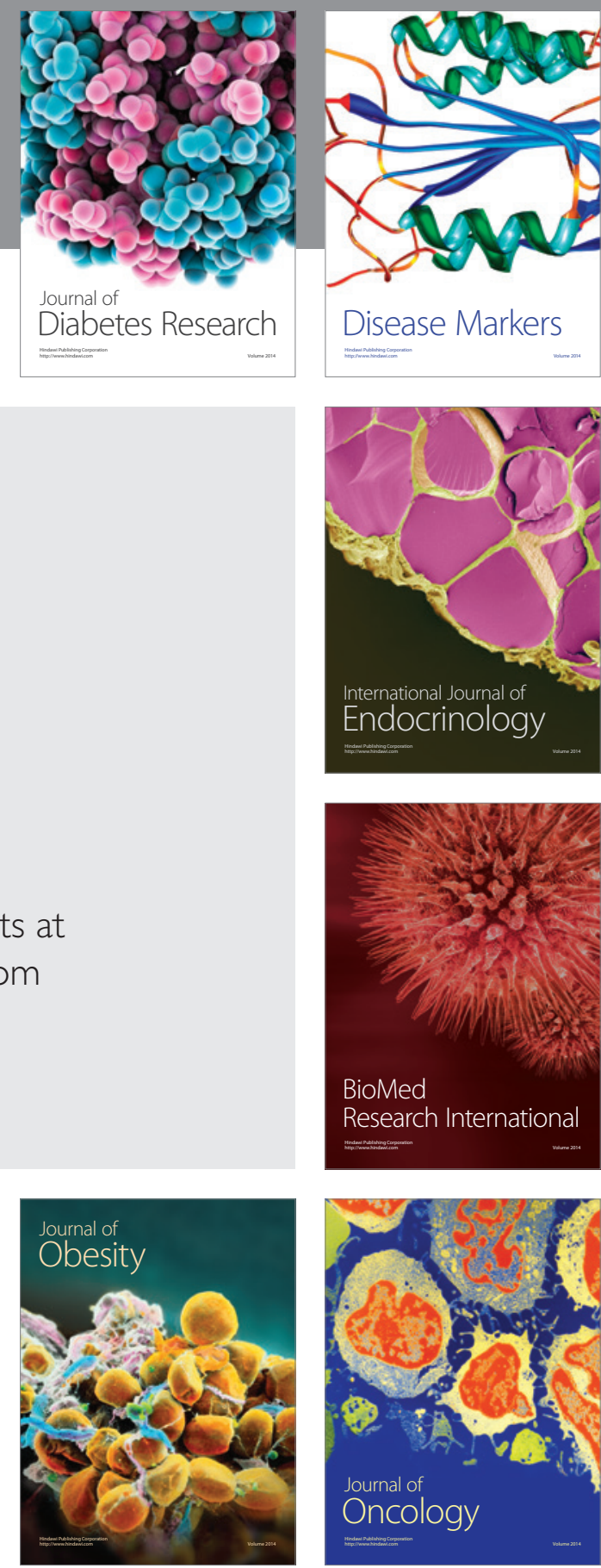

Disease Markers
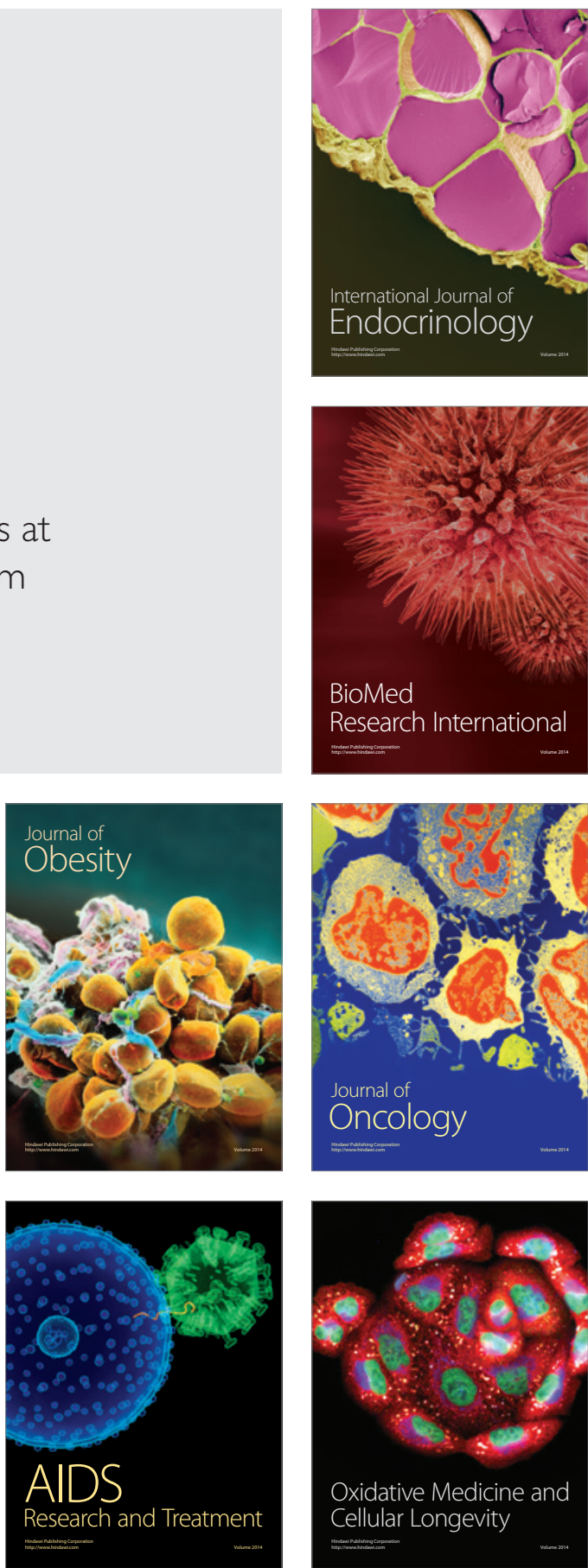